\title{
Educação clínica em enfermagem: desenvolvimento de uma casa simulada para a operacionalização de visita domiciliar
}

\section{Clinical education in nursing: development of a simulated house for the operationalization of home visits}

\section{Thiago da Silva' ${ }^{1}$ (D) Aline Carla Hennemann² (1) Thamires Souza Hilário3 ${ }^{3}$ Denise Greff Machado 4 (1) Adroaldo Lunardelli ${ }^{5}$}

1Autor para correspondência. Complexo de Ensino Superior Meridional (Porto Alegre). Rio Grande do Sul, Brasil. thipoa51@hotmail.com ${ }^{2}$ Complexo de Ensino Superior Meridional (Porta Alegre). Rio Grande do Sul, Brasil. ahennemann@yahoo.com.br ${ }^{3}$ Hospital de Clínicas de Porto Alegre (Porto Alegre). Rio Grande do Sul, Brasil. thamires.hilario@gmail.com ${ }^{4}$ Hospital Sírio Libanês (São Paulo). São Paulo, Brasil. denise.gmachado@siriolibanes.org.br ${ }^{5}$ Hospital São Lucas (Porto Alegre). Rio Grande do Sul, Brasil. adroaldolunardelli@gmail.com

\begin{abstract}
RESUMO | OBJETIVO: Relatar a construção de uma casa simulada para implementação de cenários de alta fidelidade na realização de visita domiciliar pelos acadêmicos de Enfermagem com vistas à atenção primária à saúde. MÉTODO: Relato de experiência de professores realizado no período de março de 2019 a novembro de 2020. RESULTADO: A casa simulada exigiu esforço na montagem de sua infraestrutura física, pois conta com acústica controlada, equipamentos para gravação, espelho semitransparente e mobiliário funcional. O cenário implementado trata de um atendimento de um paciente com deficiência auditiva e que apresenta hipertensão arterial. Foi utilizado, também, um aplicativo para telefone móvel que auxilia na linguagem de sinais pode ser considerada como algo funcional e proveitoso. CONCLUSÃO: O cenário estruturado apresentado mostra uma maneira elegante de trabalhar as visitas domiciliares com os estudantes, que poderão exaurir seus esforços em um ambiente controlado para dilatar suas habilidades e tornarem-se regentes de qualidade quando chegado o momento da atuação profissional.
\end{abstract}

DESCRITORES: Ensino. Simulação. Aprendizagem. Atenção primária à saúde. Visita domiciliar.

\begin{abstract}
OBJECTIVE: To report the construction of a simulated house to implement high-fidelity scenarios during home visits by nursing students with a view to primary health care. METHOD: Experience report of teachers, carried out from March 2019 to November 2020. RESULT: The simulated house required effort to assemble its physical infrastructure, as it has controlled acoustics, recording equipment, a semi-transparent mirror, and functional furniture. The implemented scenario deals with the care of a patient with hearing loss and who has high blood pressure. It was also used as an application for a mobile phone that helps in sign language can be considered something functional and useful. CONCLUSION: The presented structured scenario shows an elegant way of working home visits with students, who can exhaust their efforts in a controlled environment to expand their skills and become quality conductors when it comes to professional practice.
\end{abstract}

DESCRIPTORS: Teaching. Simulation. Learning. Primary health care. Home visit. 


\section{Introdução}

A atenção primária é a estratégia apoiada internacionalmente como elemento central e orientador de políticas que fortalecem os sistemas nacionais de saúde com abordagem integral dos indivíduos e famílias, entendendo a saúde como resultado das suas condições de vida e de trabalho. Dentre os muitos esforços que podem fazer parte da atenção primária, está a visita domiciliar (VD), que consiste no atendimento ou acompanhamento dos usuários no seu local de residência. No Brasil, a VD aparece como uma atividade realizada pelo Sistema Único de Saúde (SUS), e pode configurar-se como uma ferramenta de trabalho potente dos profissionais da saúde para compreensão contextualizada dos processos e para o delineamento de intervenções de prevenção e promoção da saúde. ${ }^{1}$ Trabalhadores de muitas expertises lançam mão da VD como tática no enfrentamento de mazelas que assolam suas comunidades e, neste panorama, o profissional de Enfermagem atua de maneira sublinhada, uma vez que tem abalizados grandes habilidades em procedimentos pertinentes a este contexto. É preciso considerar que a atenção domiciliar é uma estratégia de intervenção em saúde que requer atenção profissional qualificada, pois reconhece-se que este tipo de cuidado exige mobilização de competências específicas, principalmente ligadas ao relacionamento interpessoal para atuar com usuários, familiares e em equipe multiprofissional, bem como autonomia, responsabilidade e conhecimento técnico e científico próprios do campo.?

Para a formação de uma força de trabalho em saúde com capacidade de responder às prioridades do século XXI e atender às necessidades de atenção à saúde, atuais e futuras, se requer equilíbrio e competência na formação acadêmica dos futuros enfermeiros, devendo-se valorizar as questões ético-humanistas quanto à atenção à saúde, tomada de decisões, capacidade de comunicação e liderança. Sugere-se reconfigurações nos currículos da Enfermagem para que foquem na formação de profissionais que atuem no modelo de atenção à saúde, pontuando os indivíduos nos diferentes momentos do clico de vida, da família e da comunidade. Se reconhece a VD como um instrumento de atenção à saúde capaz de fortalecer a ampliação do olhar desses estudantes em processo de formação sobre as necessidades de saúde das pessoas, famílias e comunidade ${ }^{3}$, permitindo aos estudantes, conhecerem as condições de vida e habitação das famílias, as relações que estabelecem no ambiente doméstico, as condições de adoecimento daquela família e, consequentemente, podem facilitar o planejamento e o direcionamento das ações visando a promoção da saúde e o fortalecimento do autocuidado. ${ }^{1}$

As diretrizes curriculares implementadas nos cursos de Enfermagem (que devem fazer parte do cotidiano das instituições formadoras) têm o propósito de formar profissionais voltados a contribuir para a efetivação dos princípios e diretrizes do SUS e, assim, formar profissionais com visão ampliada para as necessidades de saúde da população. ${ }^{4}$ Cabe à academia a elaboração de estratégias que tornem o egresso competente nas articulações cabíveis ao bom desempenho do profissional no mercado de trabalho. O desenvolvimento de caminhos didáticos libertadores que tendem a distanciar-se do histórico tecnicismo irrefletido e da fragmentação de saberes é o rumo que deve ser tomado no cativo do educando. Neste sentido, o emprego da simulação realística é uma metodologia versátil, sendo possível seu uso nas mais diversas áreas, principalmente como estratégia de ensino/aprendizagem no campo da atenção primária em saúde. ${ }^{5}$

Simulação é definida como um processo dinâmico envolvendo a criação de uma oportunidade hipotética que incorpora uma representação autêntica da realidade, facilita o envolvimento ativo (do participante) e integra as complexidades da aprendizagem prática e teórica com oportunidade de repetição, feedback, avaliação e reflexão. ${ }^{6} \mathrm{~A}$ articulação da teoria e prática tem sido apontada como mecanismo eficaz no ensino superior, pois estimula o aluno na construção de um profissional promovido pela maturidade para atuar em diversas situações, além de oferecer oportunidades de aprendizagem e treinamento através da discussão reflexiva sobre a situação ocorrida ao estimular o pensando crítico e reflexivo do estudante. ${ }^{\beth}$ A educação clínica baseada em simulação é uma técnica de aprendizagem experiencial, 
que envolve colocar os alunos em situações de atendimento ao paciente criadas por instrutores, a fim de maximizar a aprendizagem em situações reais que os alunos podem encontrar.. O emprego das técnicas de simulação permite que se ofereçam as mesmas oportunidades de aprendizado, prática e treinamento para todos os estudantes de forma homogênea, sendo vista como uma forma de estudo onde a retenção do conhecimento permanece por um período mais prolongado, além de ser uma tática mais agradável e prazerosa do que o ensino tradicional. $\stackrel{9}{ }$ A experiência repetida de simulação aprimora as habilidades técnicas (tanto de baixa quanto de alta complexidade) e de pensamento crítico, tornando evidente o aumento na competência clínica dos estudantes de Enfermagem. $\frac{8}{}$

Compreendendo a relevância do papel e responsabilidade ética, técnica e social do profissional enfermeiro no contexto dos diversos cenários de assistência à saúde, bem como das necessidades exigidas pelo mundo do trabalho em saúde, aplicar estratégias educativas que desemboquem e pontuem esses aspectos é de suma relevância para formação de enfermeiros comprometidos com a vida.

O presente artigo tem como objetivo relatar a experiência de um grupo de professores na construção de uma casa simulada para a implementação de cenários de alta fidelidade na realização de visita domiciliar simulada pelos acadêmicos de Enfermagem com vistas à atenção primária à saúde.

\section{Metodologia}

Relato de experiência de docentes sobre a construção de uma casa simulada e a implementação de cenário de simulação realística de alta fidelidade, para realização de visita domiciliar (VD) na atenção primária à saúde.

No caso relatado, o cenário de simulação foi o atendimento de um paciente com deficiência auditiva e hipertensão arterial sistêmica (HAS) em uso contínuo de fármaco anti-hipertensivo. Um ator faz as vezes do sujeito paciente, enquanto os acadêmicos realizam o atendimento como enfermeiros.

A atividade aqui descrita foi realizada em um ambiente pertencente ao laboratório universitário de alta fidelidade para fins de simulação em Enfermagem e, ao se oportunizar um ambiente de galhardia como este, pode-se compartilhar a estrutura com outras demandas da entidade, como por exemplo, os cursos de Psicologia, Farmácia, Medicina, Nutrição, Odontologia e Fisioterapia.

Indubitavelmente, são muitas as possibilidades de temas e situações que podem ser desenvolvidas nessa estruturação. A construção de um cenário de simulação realística se dá apoiada no desenvolvimento de três peças-chave, sumarizadas em escopo (o conteúdo que será abrangido na simulação), modalidade (se a simulação se dará por meio de jogos interativos, por meio de manequins ou atores treinados, por exemplo) e ambiente (os materiais e meios utilizados para aproximar a simulação das situações reais). $\cdot^{10}$

O emprego desta metodologia e a construção de cenários realísticos não exige, necessariamente, altas tecnologias e manequins de alta resposta. O professor deve enfocar nos resultados a serem atingidos segundo seu plano, sendo que o desenho da atividade de simulação considerará a especificidade, mensurabilidade e abrangência da ação.

\section{Resultados e discussão}

A casa simulada, aqui exposta, exigiu um esforço econômico institucional para a montagem de sua infraestrutura física, pois conta com ambiente climatizado, acústica controlada, equipamentos para gravação (de áudio e vídeo), sala espelhada e mobiliário funcional. $\mathrm{O}$ perfil arquitetônico do espaço é apresentado na Figura 1. O espaço foi concebido de maneira a representar o ambiente domiciliar com fidelidade e excelência. 
Figura 1. Disposição arquitetônica da casa simulada para realização de cenários simulados de visita domiciliar. (I) Sala de observação donde cadeiras acomodam os espectadores da cena. Na sala onde ocorre a simulação, o mobiliário funcional real conta com (II) sofá; (III) bancada com pia e fogão; (IV) mesa de jantar; e (V) cama de casal. Uma sala de controle (VI) adjacente é ocupada com as tecnologias necessárias para os comandos de áudio e vídeo

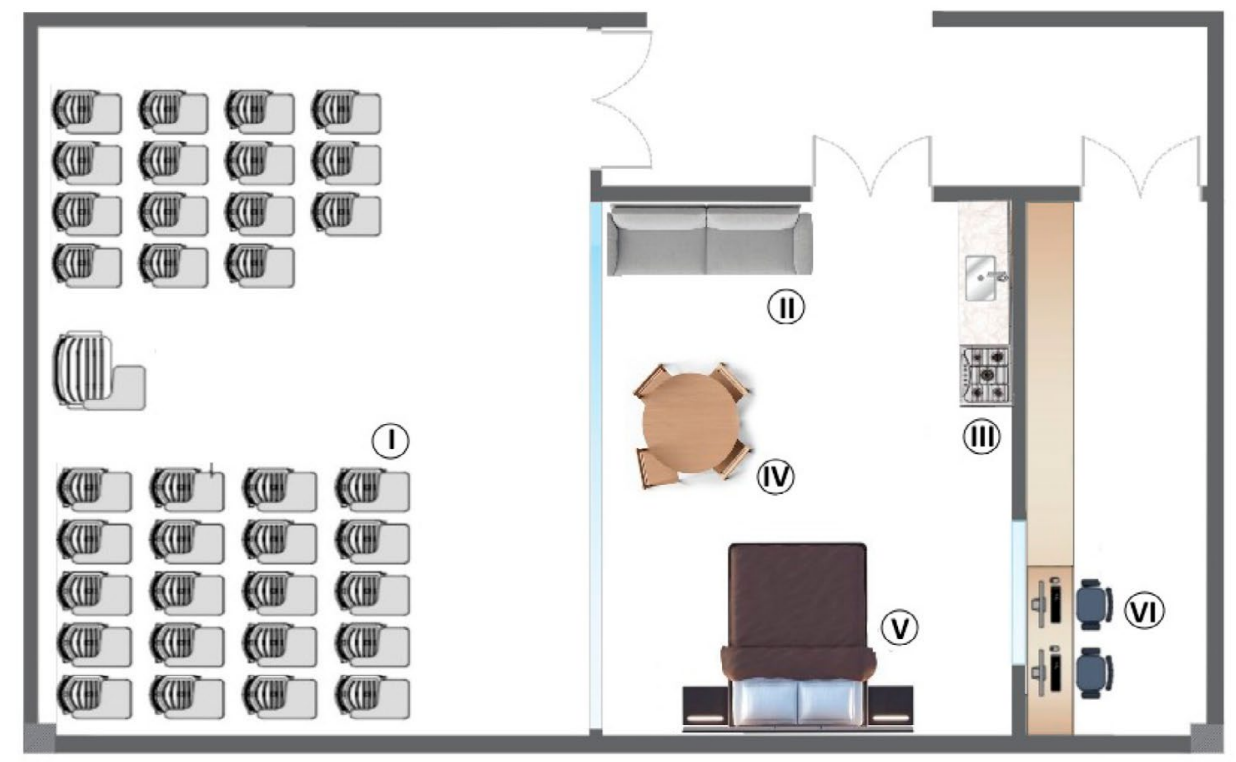

A visita domiciliar simulada é uma abordagem que deve ser realizada pelo enfermeiro que atua na atenção primária à saúde, estando previsto no ensino para Enfermagem segundo a diretriz curricular nacional expedida pelo Ministério de Educação e Cultura em 2001, onde a estrutura do curso de graduação deve utilizar diferentes cenários de ensino e aprendizagem em equipe multiprofissional, permitindo ao aluno conhecer e vivenciar situações variadas da vida, da organização da prática e do trabalho.

Tais condições de primazia não são, certamente, possíveis à realidade de todas as instituições de ensino, entretanto, adaptações podem ser facilmente realizadas para que o cenário possa ser construído de forma a se adequar às possibilidades e anseios de cada escola. O apresentado aqui torna-se, portanto, um gabarito maleável muito ajustado aos anseios do curso de Enfermagem, mas que se incorpora com facilidade a outros cursos e possibilidades. Toda a infraestrutura é segmentada em três espaços, todos com climatização e acessibilidade à cadeirantes.

O primeiro deles é uma sala de observação com área de $69,3 \mathrm{~m}^{2}$, donde os alunos expectadores podem observar o cenário confortavelmente acomodados em cadeiras com braço, o que permite comodidade para anotações. 0 áudio é perceptível por caixas de som que podem ter o volume regulado. Esta sala é separada da sala de simulação por um vidro semitransparente, o que significa que os alunos instalados na sala de observação conseguem ver com perfeição os indivíduos no cenário, todavia, o contrário não ocorre. A sala de simulação possui $46,4 \mathrm{~m}^{2}$ e conta com mobiliário real (sofá, cama, mesa de jantar, pia e fogão), sistema de captação de áudio (microfone) e vídeo (câmera) e - como mencionado anteriormente - isolamento acústico e visual. Os equipamentos para gravação de áudio e vídeo são fecundos materiais para estudo e análise posterior ao fato, podendo ser destrinchado conforme a necessidade de resgate de conteúdo. 
Os estudantes que perfazem a atividade, portanto, não se deixam influenciar por possíveis reações dos alunos que compõem a plateia, uma vez que o vidro semitransparente não permite a visualização das salas adjacentes.

Por fim, há uma sala de controle com área de $18,2 \mathrm{~m}^{2}$, cuja função primordial é o manejo tecnológico do episódio, uma vez que se pode manipular a luz, o som e as gravações em mídia. Esta sala também possui um vidro semitransparente donde quem está nela tem contato visual com a sala da cena, contudo, o contrário não é verdadeiro.

\section{Construção e aplicabilidade do cenário}

Entre os pontos a serem considerados durante a construção do cenário e a determinação dos objetivos estão as habilidades e competências necessárias para a resolução da situação clínica.

Na construção da situação, elaboram-se os detalhes do caso clínico, tais como local, as características do paciente, os dados do exame físico e as respostas fisiológicas que acontecerão no decorrer do cenário de acordo com a conduta dos participantes. No planejamento dos recursos necessários deve-se identificar todos os expedientes materiais e humanos indispensáveis à sua adequada execução. $\frac{11}{}$ Sublinha-se a importância que deve ser dada ao treinamento instrucional para os atores. Estes se mostram peças-chave no desenrolar de uma simulação.

Anteriormente à realização da atividade, é importante a familiarização dos estudantes com a tecnologia e os equipamentos nele envolvidos. O aluno precisa conhecer/entender como o processo funciona para bem poder interagir com a sistemática do cenário, identificando de maneira clara o que deve e o que não deve fazer.

O tempo de duração prevê a estimativa de uma hora para cada cenário, distribuídos entre as sessões de briefing, simulação e debriefing. É importante o controle do tempo de realização das atividades simuladas pelo professor/facilitador, sinalizando seu término com um sinal previamente acordado com os alunos. Pode-se interromper a cena caso o limite de tempo seja extrapolado para, em seguida, dar continuidade às outras etapas da sessão ${ }^{12}$, caso se faça necessário.

É fundamental que o aluno atente ao tempo pré-estipulado para atividade simulada, compreendendo o papel do docente em caso de interrupção da cena após ultrapassar o tempo previsto. Cabe ressaltar que o fator determinante do tempo depende do público alvo, dos objetivos a serem atingidos e da logística que cada tarefa demanda. Quando da construção da atividade, o professor deve, com muita atenção, estipular o tempo que os alunos dispensarão a cada empreitada de maneira confortável, não deixando tempo ocioso (o que minimizaria o desempenho do estudante) e nem espaços muito justos (o que poria o aluno em desconfortável pressão).

Certamente, o sucesso da experiência calca-se, num primeiro momento, na habilidade do educador em produzir um correto desenho de construção da atividade. Nesta seara, uma documentação firme é imprescindível. A descrição do passo-a-passo deve ser bem documentada, e os instrumentos de acompanhamento devem ser bem estruturados. A figura 2 mostra o modelo utilizado na aplicabilidade do cenário. 
Figura 2. Modelo de instrumento utilizado para construção e aplicabilidade de cenários

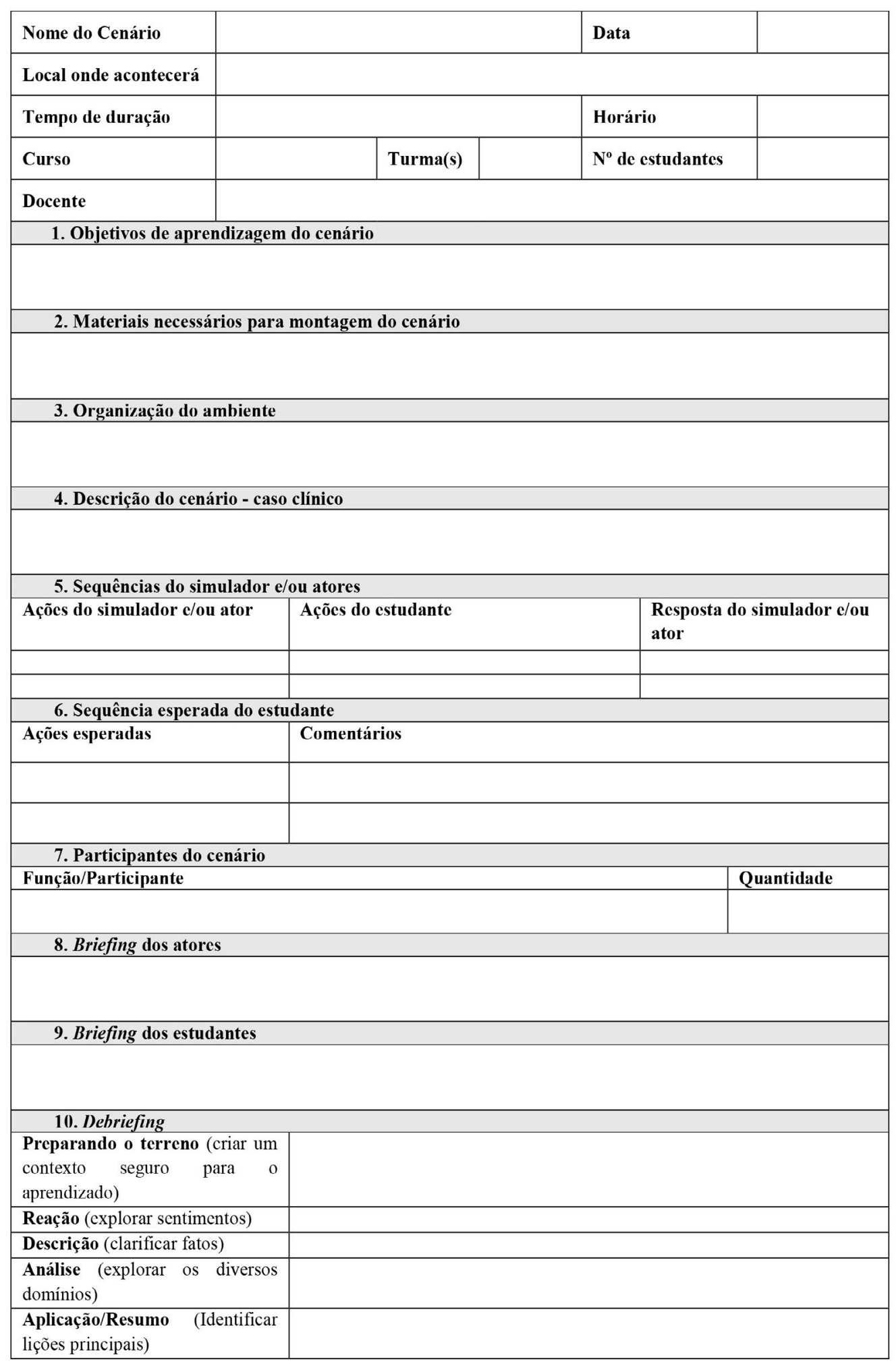


Alterações que contemplem singularidades requeridas são de fácil realização, desde que sejam planejadas com a antecedência que o preparo exige. A montagem e o encaixe de todas as peças devem levar em consideração as ações (e reações) que se esperam dos alunos, fazendo com que as tomadas de decisão dos mesmos os encaminhem para contemplar o atingimento dos objetivos de aprendizagem.

Como exemplos de objetivos de aprendizagem para este cenário, podemos aludir: realizar diagnósticos de enfermagem relacionados a saúde do sujeito portador de HAS; planejar assistência de Enfermagem integral ao sujeito em todos os níveis de saúde, de forma sistematizada e segura, considerando o perfil epidemiológico da população e os aspectos sociais, étnicos, raciais e culturais; implementar cuidados e ações de educação em saúde de maneira que seja possível promover a qualidade de vida, prevenir doenças e reabilitar a saúde do debilitado; e orientar em relação ao uso correto da medicação e a participação em grupo de apoio para portadores de HAS.

\section{Plataforma de tradução simultânea}

Para o aumento da complexidade do cenário, utilizamos uma ferramenta tecnológica, o aplicativo denominado de Hand Talk (mãos que falam, na tradução literal), que pode ser utilizado durante uma visita domiciliar para estabelecer uma comunicação segura quando se trata de pacientes com necessidades especiais auditivas. A figura 3 mostra a interface do aplicativo.

Figura 3. Interface do aplicativo Hand Talk

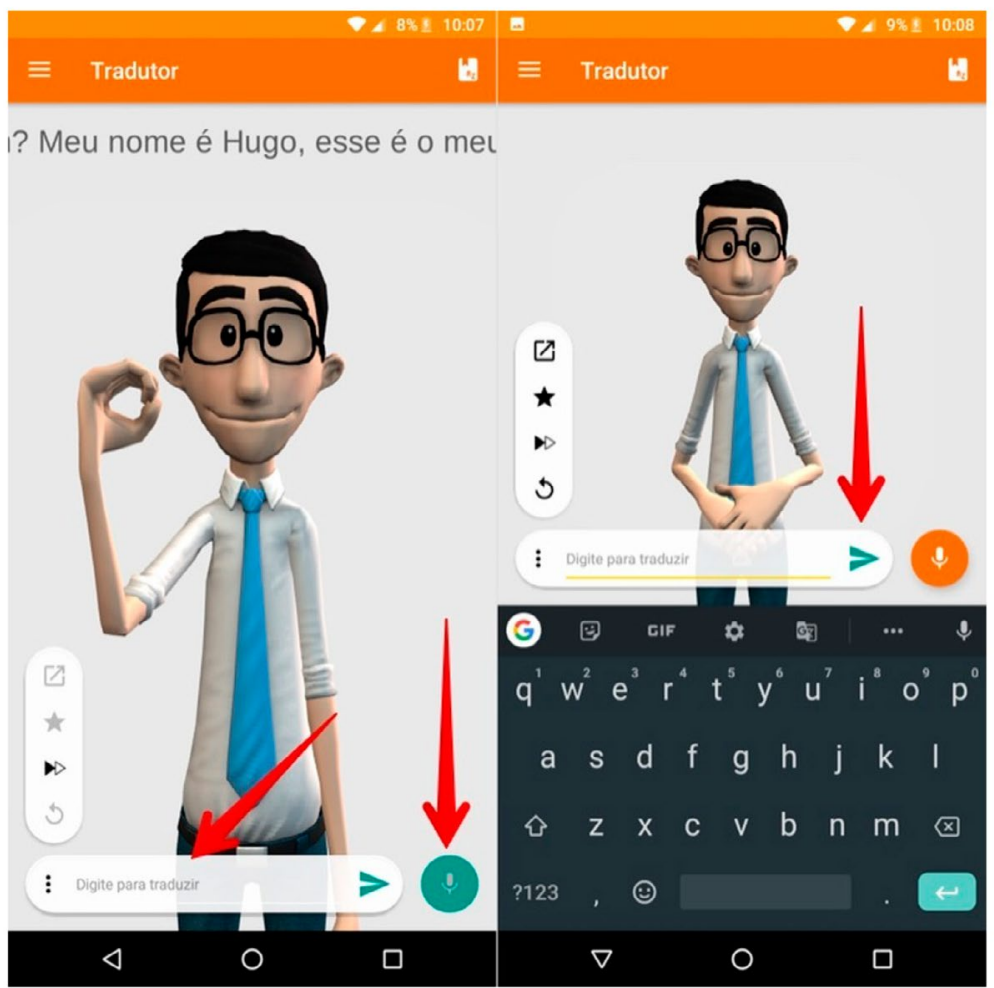


É uma ferramenta gratuita desenvolvida para os sistemas operacionais de smartphones voltada para conversão de áudios e textos fotográficos para a linguagem de sinais. $O$ aplicativo não é só um dicionário ou tradutor gramatical da língua portuguesa para a Língua Brasileira de Sinais (Libras), uma vez que através de uma biblioteca de animação, programada por um conjunto de mais de 300 palavras, o software converte dados de texto, som e imagem que são traduzidos em Libras. Além de ser uma grande opção de acessibilidade, o tradutor pode ser utilizado por pessoas de todas as idades, com deficiência ou não, que queiram aprender e se comunicar utilizando a Libras. Em 2013, o aplicativo alagoano Hand Talk venceu o prêmio da Organização das Nações Unidas de melhor aplicativo de inclusão social do mundo.

\section{Debriefing}

O debriefing é um critério de boas práticas em simulação, sendo que a elaboração de um roteiro com os objetivos, pontos críticos do cenário e perguntas que podem direcionar a discussão, permitem que ele possa ser conduzido pelo facilitador ${ }^{13}$, outrossim, esta conversa facilitada após o evento (clínico ou simulado) tem o objetivo de melhorar a prática clínica futura.

Recomenda-se que o debriefing seja conduzido de forma estruturada e contribua para o aprendizado do estudante. A reflexão dos estudantes consiste em um elemento essencial no desenvolvimento das competências profissionais e implica assimilar conhecimento, habilidades e atitudes com o conhecimento pré-existente.

A realização do feedback do ator participante, ao término do cenário, com comentários de como se sentiu no papel desempenhado é importante para a formação do aluno.

Para este cenário, utilizamos a estrutura PEARLS (Promovendo Excelência e Aprendizagem Reflexiva na Simulação). O roteiro de debriefing PEARLS é uma ajuda cognitiva que pode promover os esforços de desenvolvimento do corpo docente e aumentar as habilidades de debriefing, especialmente para os educadores que ainda estão solidificando sua experiência em debriefing. 14
Na maior parte das instituições de ensino, salvo algumas exceções, a simulação tem sido apoiada por simuladores de baixa fidelidade em razão de gestão acadêmica ineficiente, escassez de recursos das escolas ou sua subutilização; reconhece-se, porém, algumas exceções, geralmente, frutos da criatividade e arte que desde cedo caracterizaram os enfermeiros, além da liderança e o empreendedorismo de alguns gestores e docentes. $\cdot \frac{15}{}$

O desenvolvimento de uma casa simulada não se sujeita, necessariamente, ao poderio econômico que se possa dispender para sua implantação. Mais do que isso, depende de um alinhamento fino entre os objetivos de aprendizagem que se deseja alcançar e a engenhosidade em propor um cenário adequado.

A situação clínica - personificada aqui na abordagem de um sujeito com diagnóstico de HAS (uma doença crônica não transmissível) em uso de medicação contínua - demanda o desenvolvimento técnico de atitudes que devem ser desenvolvidas no estudante de Enfermagem no apoio e acompanhamento ao paciente, visando a promoção de saúde e o bem-estar. Adiciona-se a este cenário já desafiador, o degrau das necessidades especiais, uma vez que o discente precisa desenvolver uma estratégia de convencimento ao usuário (que é deficiente auditivo) para fazer uso de um aplicativo de telefone, facilitando a comunicação e orientação em relação ao uso correto da sua medicação e a sua participação em um grupo de apoio para portadores de HAS.

Ao final do caso, uma discussão conduzida pelos docentes aborda os aspectos observados pelos estudantes, possibilitando a testagem simultânea de múltiplos domínios: assistência, profissionalismo, conhecimento e competências individuais (postura e comunicação, por exemplo). Através desse processo, os acadêmicos podem identificar fragilidades em suas performances, otimizando a obtenção de meIhores resultados na prática clínica.

A simulação com caso clínico propicia um espaço de raciocínio diagnóstico em Enfermagem, com a apresentação de intervenções mediante a avaliação do histórico do paciente simulado. Toda essa cena desenhada possui alto grau de dificuldade e grande potencial para o amadurecimento do futuro enfermeiro. 
A utilização da simulação atribuída a formação, possibilita aos alunos desenvolverem habilidades e competências necessárias nos ambientes de prática real, proporcionando aumento de confiança e maior engajamento do estudante em relação a sua conduta, decorrente da vivência de diversas situações comuns na assistência, mas muitas vezes impossíveis na prática clínica real durante a graduação; ademais, evita que os usuários sejam colocados em situações de risco por inexperiência dos estudantes. $\frac{16}{}$

As estratégias de ensino/aprendizagem em instituições de ensino superior devem, portanto, buscar romper a lógica do ensino focado na transmissão de conhecimentos de maneira vertical e ir além da metodologia tradicional, buscando usar métodos ativos, com ênfase em situações-problema, estudos de casos clínicos, aprendizagem em grupo e aulas participativas com utilização de novas tecnologias para o ensino. ${ }^{17}$

A abordagem inovadora, na qual o estudante é o protagonista das ações em sala de aula, deve ser tida como pilar de desenvolvimento pedagógico nas instituições de ensino superior desde as séries iniciais. Tanto para escolas possuidoras de matriz curricular interdisciplinar (baseado em eixos integradores divididos em blocos de conhecimento) quanto para aquelas que seguem a divisão de disciplinas tradicional, quanto antes o aluno for colocado como parte da engrenagem dinâmica da sala de aula, mais adaptado ele estará na continuidade do processo e menor será a resistência às metodologias que evitam a passividade de uma aula puramente expositiva. ${ }^{18}$

A simulação ativa envolve uma recriação da prática clínica com o uso de novas tecnologias de forma orientada, permitindo uma abordagem alternativa da realidade. As variações dos cenários expõem os alunos a uma diversidade de problemas, permitindo desenvolvimento integrado na capacidade de resolução e compreensão do contexto clínico-social do paciente ${ }^{19}$, devendo-se contemplar a capacidades de trabalho em equipe, o gerenciamento de crise e a liderança, uma vez que, além da órbita teórica e das habilidades técnicas, a postura atitudinal deve ser coordenada simultaneamente, facilitando a transferência do que foi aprendido para a solução de novos problemas. $\stackrel{9}{ }$
Quando os estudantes são confrontados com a possibilidade de colocarem em prática o que veem descrito nos livros, sentem-se estimulados a construir o seu conhecimento e viverem intensamente essa experiência dinâmica, aproximando-os de um modelo mais construtivista. Esta interatividade é fonte de motivação por considerarem que após a experiência simulada, a sua aprendizagem melhora por ser considerada autêntica, por refletir a realidade, e contribuir para a participação do estudante na sua própria aprendizagem.

Apesar das experiências clínicas simuladas não substituírem as vivências que se podem obter no contato com um doente real, elas podem ser uma mais-valia na melhoria dos conhecimentos sobre o universo que orbita a prática, principalmente durante uma visita domiciliar, sendo que este conhecimento pode ser potencializado quando se associa a aula teórica com a simulação, mesmo perante estudantes que estão no início da sua formação acadêmica. 20

A simulação, durante essa experiência, apresenta contribuições ao ensino das práticas avançadas de Enfermagem para o desenvolvimento de competências de manejo clínico evoluído, incluindo habilidades de liderança e de trabalho em equipe. Além disso, contribui para o preenchimento de lacunas do aprendizado voltadas a atuação do enfermeiro na atenção primária à saúde com foco na VD, estimulando o uso das evidências científicas e o desenvolvimento do raciocínio clínico.

A metodologia de simulação realística possibilita emergir o saber ser estar do sujeito, sendo um elemento dinamizador fundamental, em aspecto constitutivo da realidade recriada nos cenários instituídos, colocando-os em uma condição de autonomia na tomada de decisão; convergindo com o pensamento de Piaget, que afirma que o sujeito atua e pensa, mediante os objetos resultantes de suas experiências, pontuando que a apropriação do conhecimento só é possível através das atividades dos organismos sobre o objeto. 21 
As situações reais com pacientes sempre serão essenciais para expor os alunos a realidade complexa da prática. A utilização da simulação, quando bem estruturada, representa uma modalidade complementar adicional que não exclui a necessidade da prática direta com pacientes reais. $\mathrm{O}$ envolvimento direto com o paciente cria um elo entre o profissional e o usuário dos serviços de saúde, gerando uma rede complexa de respostas conscientes e inconscientes, que incluem habilidades interpessoais, como empatia e comunicação efetiva.

Nesse contexto, o ensino por meio da simulação possibilita a preparação segura dos alunos para que atuem posteriormente de forma efetiva, protegendo, como consequência, a saúde dos usuários dos serviços de saúde e evitando a ocorrência de erros. Com a simulação, os alunos podem praticar e cometer menos erros, sem que isso ofereça riscos para os pacientes e para os próprios alunos. $\underline{.2}$

A eficácia do método da simulação traz inúmeros resultados positivos para o aluno, o qual passa a ser o sujeito ativo da ação que deve ser feita por meio do desenvolvimento do pensamento crítico e lógico. O ensino por meio de simulação pode ser considerado um instrumento interessante para lidar com tensões éticas e dilemas práticos, uma vez que valoriza o aprendizado com base na experiência prática e vem sendo cada vez mais aceito e solicitado por alunos. Ainda dentre os aspectos positivos, podemos citar a diminuição da ansiedade dos futuros profissionais, o sentimento de que possuem as competências necessárias para desempenhar suas funções e a redução da lacuna entre a teoria e a prática. $\underline{\underline{23}}$

É bem documentado que a simulação no ensino de Enfermagem clínica melhora as habilidades de avaliação, de comunicação, de gerenciamento e psicomotoras, oportunizando a prática clínica e a tomada de decisão por meio de experiências situacionais da vida real variadas, sem comprometer a segurança do

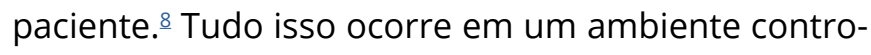
lado e despressurizado.

Invocar um ambiente de estudo agradável e dinâmico torna o aprendizado muito mais adequado, prazeroso e efetivo. $\frac{18}{\mathrm{O}}$ encanto ocorre quando o estudante está tão mergulhado na ação, que nem percebe o quanto aprende da lição que estava sendo pontuada.
O aprendizado torna-se fluido e espontâneo. Quando é chegado o momento da prática na vida profissional, o sujeito se dá por conta do quanto pôde assimilar em um modelo prazeroso e eficaz. Neste momento então, satisfaz-se ao atinar-se sabido, como se fosse uma gota d'água descobrindo que é um mar azul.

A utilização de um aplicativo que auxilia na linguagem de Libras pode ser considerada como algo funcional e proveitoso, sobretudo para uma interação mais rápida entre o enfermeiro e o paciente. Entendemos, todavia, que apenas o aplicativo não é suficiente para compreensão ideal dos pacientes com deficiência auditiva, uma vez que a tradução não leva em consideração o regionalismo e até mesmo as gírias utilizadas, principalmente, pelo público mais jovem.

Mesmo com limitações, o uso dessa tecnologia permite a inclusão do paciente como protagonista do seu cuidado de forma mais inclusiva, digna e com qualidade. Nesse cenário, o profissional de Enfermagem pode atuar como multiplicador do conhecimento em saúde auditiva. Para tanto, esses profissionais devem aprender, por meio de processos de aprendizagem continuada, e estar preparados para atender e dar suporte integral à saúde da população por meio de ações de educação em saúde. ${ }^{24}$ Desponta aqui a advertência acerca da imprescindibilidade de profissionais da Enfermagem capacitados e com experiência no manejo de pessoas portadores de deficiência, uma demanda antiga que permanece na vazante das escolas preparatórias.

A experiência simulada pode oferecer aos alunos maior suporte ao aprendizado clínico, direcionando as atividades simuladas para as necessidades de aprendizado específicas, até mesmo na avaliação de desempenho.

No debriefing, os estudantes valorizam as reflexões dirigidas, tomando lições que sedimentam a experiência. O debriefing é um momento de suma importância na gestão do atingimento dos objetivos propostos pela simulação. Há reflexões centradas em si (eu, como estudante, analiso meu desempenho nas tomadas de decisão), focadas na ação (consciência e assertividade da ação), visando a relação (interação com a equipe e cliente) e pontuadas na criação de novas ações (desejo e fortalecimento de novas atitudes). 
O debriefing é central como um evento de foco, pois é o momento onde, muitas vezes, os alunos expressaram decepção com seus desempenhos e a orientação do corpo docente norteia o pensamento para um ambiente seguro e de confiança. $\frac{25}{\mathrm{O}} \mathrm{O}$ olhar em si, o pensamento crítico na ação e a consciência de equipe precisam ser revistas com a apropriação do aprendizado e com a convicção de que pode haver crescimento atitudinal para desfechos mais certeiros.

\section{Conclusão}

As novas formas de aprendizagem no ensino superior vêm se moldando com o passar do tempo e sendo incorporadas aos cursos de graduação, criando um ambiente propício para que o acadêmico tenha a possibilidade de ser resolutivo frente a um desafio, impactando no perfil profissional que está em consonância com as competências gerais dos modernos profissionais da saúde.

Este trabalho mostra uma elaborada e planejada rota de estruturação de uma casa simulada para o desenvolvimento de simulações realísticas com foco no estudante do curso de Enfermagem, numa necessidade acadêmica de aperfeiçoamento das competências e habilidades imperativamente indispensáveis na execução de visita domiciliar, sendo esta, uma importante fatia das ações voltadas à atenção primária em saúde.

As simulações realísticas são capacitações na própria academia que têm como objetivo treinar os estudantes, capacitando-os para a assistência ao paciente. O cenário estruturado apresentado neste trabalho demonstra uma maneira elegante de trabalhar as visitas domiciliares - uma prerrogativa de ímpar importância na atenção primária em saúde - para os acadêmicos de Enfermagem, que poderão exaurir seus esforços em um ambiente controlado para dilatar suas habilidades e tornarem-se regentes de qualidade quando chegado o momento de atuar como enfermeiros.

Destaca-se neste desígnio, que este certame foi construído e concebido como um cenário de excelência para a execução de seus objetivos, entretanto, pode ser tomado como base por outras instituições e modificado de acordo com as singularidades de cada proposta e particularidades de cada comarca. Estudos que mostram casos de sucesso como este, são de ímpar importância na troca de experiências entre docentes, o que contribui para ensejar amplos leques de possibilidades didáticas que culminem na sublime formação profissional dos egressos.

\section{Contribuições dos autores}

Hennemann AC, Hilário TS, Machado DG, Silva T e Lunardelli A participaram do desenho do estudo e de sua elaboração prática. Hennemann AC e Hilário TS participaram da revisão referencial bibliográfica e da construção intelectual do trabalho. Machado DG e Silva T participaram da concepção do trabalho, delineamento do estudo e interpretação dos dados. Lunardelli A participou da interpretação dos resultados, redação e revisão crítica do artigo científico. Os autores aprovam a versão final a ser publicada, estão de acordo com todos os seus aspectos e garantem sua precisão e integridade.

\section{Conflito de interesses}

Nenhum conflito financeiro, legal ou político envolvendo terceiros (governo, empresas e fundações privadas, etc.) foi declarado para nenhum aspecto do trabalho submetido (incluindo, mas não se limitando a subvenções e financiamentos, participação em conselho consultivo, desenho de estudo, preparação de manuscrito, análise estatística, etc.).

\section{Referências}

1. Rocha KB, Conz J, Barcinski M, Paiva D, Pizzinato A. A visita domiciliar no contexto da saúde: uma revisão de literatura. Psicol saúde doenças [Internet]. 2017;18(1):170-85. Disponível em: https://www.redalyc.org/articulo.oa?id=36250481015

2. Andrade AM, Silva KL, Seixas CT, Braga PP. Atuação do enfermeiro na atenção domiciliar: uma revisão integrativa da literatura. Rev Bras Enferm. 2017;70(1):210-9. https://doi. org/10.1590/0034-7167-2016-0214
3. Marin MJS, Gomes R, Siqueira Junior AC, Nunes CRR, Cardoso $\mathrm{CP}$, et al. O sentido da visita domiciliária realizada por estudantes de medicina e enfermagem: um estudo qualitativo com usuários de unidades de saúde da família. Ciên saúde coletiva. 2011;16(11):4357-65. http://dx.doi.org/10.1590/S1413- $\underline{81232011001200008}$ 
4. Winters JRF, Prado ML, Heidemann ITSB. A formação em enfermagem orientada aos princípios do Sistema Único de Saúde: percepção dos formandos. Esc Anna Nery. 2016;20(2):248-53. https://doi.org/10.5935/1414-8145.20160033

5. So HY, Chen PP, Wong GKC, Chan TTN. Simulation in medical education. J R Coll Physicians Edinb. 2019;49(1):52-7. https://doi. org/10.4997/jrcpe.2019.112

6. Husebø SE, Silvennoinen M, Rosqvist E, Masiello I. Status of Nordic research on simulationbased learning in healthcare: an integrative review. Adv Simul (Lond). 2018;3:12. https://doi. org/10.1186/s41077-018-0071-8

7. Ferreira RPN, Guedes HM, Oliveira DWD, Miranda JL. Simulação realística como método de ensino no aprendizado de estudantes da área da saúde. Rev Enferm Centro-Oeste Min. 2018;8:e2508. https://doi.org/10.19175/recom.v8i0.2508

8. Gharibi KAA, Arulappan J. Repeated simulation experience on self-confidence, critical thinking, and competence of nurses and nursing students - an integrative review. SAGE Open Nurs. 2020;6:1-8. https://doi.org/10.1177/2377960820927377

9. Brandão CFS, Collares CF, Marin HF. A simulação realística como ferramenta educacional para estudantes de medicina. Sci Med [Internet]. 2014;24(2):187-92. Disponível em: https:// pesquisa.bvsalud.org/portal/resource/pt/lil-742489

10. Yamane MT, Machado VK, Osternack KT, Mello RG. Simulação realística como ferramenta de ensino na saúde: uma revisão integrativa. Rev Espaço para Saúde. 2019;20(1):87-107. https://doi. org/10.22421/15177130-2019v20n1p87

11. Cogo ALP, Lopes EFS, Perdomini FRI, Flores GE, Santos MRR. Construção e desenvolvimento de cenários de simulação realística sobre a administração segura de medicamentos. Rev Gaúcha Enferm. 2019;40(spe):e20180175. https://doi.org/10.1590/19831447.2019 .20180175

12. Oliveira ICM, Melo GSM, Costa IKF, Torres GV. Contribuições da simulação para o processo de ensino-aprendizagem da graduação em enfermagem: revisão interativa. Arq. Ciênc. Saúde [Internet]. 2014;21(3):9-15. Disponível em: https://repositorio-racs. famerp.br/racs_ol/vol-21-3/IDZ-575-(21-3)-jul-Se-2014.pdf

13. Fanning RM, Gaba DM. The role of debriefing in simulationbased learning. Simul Healthc. 2007;2(2):115-25. https://doi. org/10.1097/sih.0b013e3180315539

14. Eppich W, Cheng A. Promoting Excellence and Reflective Learning in Simulation (PEARLS): development and rationale for a blended approach to health care simulation debriefing. Simul Healthc. 2015;10(2):106-15. https://doi.org/10.1097/ sih.0000000000000072
15. Martins JCA, Mazzo A, Batista RCN, Coutinho VRD, Godoy $S$, Mendes IAC, et al. A experiência clínica simulada no ensino de enfermagem: retrospectiva histórica. Acta Paul Enferm. 2012;25(4):619-25. https://doi.org/10.1590/S010321002012000400022

16. Waterkemper R, Prado ML. Estratégias de ensinoaprendizagem em cursos de graduação em Enfermagem. Av Enferm. 2011;29(2):234-46. http://www.scielo.org.co/scielo. php?pid=S0121-45002011000200003\&script $=$ sci abstract\&tIng=pt

17. Jansson MM, Syrjälä HP, Ohtonen PP, Meriläinen $M H$, Kyngäs HA, Ala-Kokko TI. Effects of simulation education on oral care practices - a randomized controlled trial. Nurs Crit Care. 2017;22(3):161-8. https://doi.org/10.1111/nicc.12276

18. Lunardelli A. Machado DG. Dinâmica ativa em sala de aula no ensino-aprendizado da transcrição gênica em ciências da saúde. Metodologias e Aprendizado. 2020;2:122-31. https://doi. org/10.21166/metapre.v2i0.1350

19. Crowe S, Ewart L, Derman S. The impact of simulation based education on nursing confidence, knowledge and patient outcomes on general medicine units. Nurse Educ Pract. 2018;29:70-5. https://doi.org/10.1016/j.nepr.2017.11.017

20. Schiavenato M. Reevaluating simulation in nursing education: beyond the human patient simulator. J Nurs Educ. 2009;48(7):38894. https://doi.org/10.3928/01484834-20090615-06

21. Piaget J. O desenvolvimento do pensamento: equilibração das estruturas cognitivas. Lisboa: Dom Quixote; 1977.

22. Mccallum J. The debate in favour of using simulation education in pre-registration adult nursing. Nurse Educ Today 2007;27(8):825-31. https://doi.org/10.1016/j.nedt.2006.10.014

23. Ziv A, Wolpe PR, Small SD, Glick S. Simulation-based medical education: an ethical imperative. Acad Med. 2003;78(8):783-8. https://doi.org/10.1097/00001888-200308000-00006

24. Barbosa CP, Aires JB, Farias IYS, Linhares FMP, Griz SMS. Educação em saúde auditiva do neonato e lactente para profissionais de enfermagem. Braz J Otorhinolaryngol. 2013;79(2):226-32. https://doi.org/10.5935/1808-8694.20130039

25. Mcniesh SG. Cultural norms of clinical simulation in undergraduate nursing education. Glob Qual Nurs Res. 2015;2:110. https://doi.org/10.1177/2333393615571361 